\title{
Antigenicity and immunogenicity of recombinant envelope glycoproteins of SIVmac32H with different in vivo passage histories
}

\author{
Ellen G.J. Hulskotte*, Guus F. Rimmelzwaan†, Jolande Boes*,

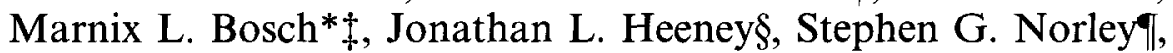 \\ Petra de Vries* and Albert D.M.E. Osterhaus* ${ }^{*} \|$
}

Shortly after infection of two rhesus monkeys (Macaca mulatta) either with a SIVmac $32 \mathrm{H}$ challenge stock or with the same virus that had been passaged in another rhesus monkey for 11 months, SIV-envelope genes were cloned from their peripheral blood mononuclear cells and subsequently expressed by recombinant vaccinia viruses. The molecular weights and antigenicities of the thus produced envelope glycoproteins were largely identical to those of the native SIV. The envelope glycoprotein derived from the in vivo passaged virus proved to be poorly recognized by virus neutralizing monoclonal antibodies directed against one of the seven antigenic sites for which monoclonal antibodies were available. Immunization studies in rats showed that this protein was also less efficient in inducing antibodies against this antigenic site, and that it induced significantly lower levels of virus neutralizing antibodies than the other SIV-envelope glycoprotein. The immunogenicity of the SIV-envelope glycoprotein incorporated into immune stimulating complexes (iscoms) was compared to that of the same protein presented with Quil A or MDP-tsl.

Keywords: SIV: SIV-envelope glycoprotein; antigenicity

Simian immunodeficiency virus (SIV) and human immunodeficiency virus (HIV) are closely related lentiviruses which show similarities both in their genomic organization and in the disease they cause in their respective hosts ${ }^{1}$. Therefore SIV infection of macaques is considered a suitable model for HIV infection in humans to study pathogenesis and development of passive and active immunization strategies.

\footnotetext{
*Laboratory of Vaccine Development and Immune Mechanisms, National Institute of Public Health and Environmental Protection, PO Box 1, 3720 BA Bilthoven, The Netherlands. fInstitute of Virology, Erasmus University Rotterdam, PO Box 1738, 3000 DR Rotterdam. The Netherlands. \$Present address: Regional Primate Research Center \& Department of Pathology, University of Washington, I-421 Health Sciences Center SJ-50, Seattle, WA 98195, USA. §Laboratory of Viral Pathogenesis, Biomedical Primate Centre, PO Box 5815, 2280 HV Rijswijk, The Netherlands. TDepartment of Immunology, Paul-Ehrlich Institute, Paul-Ehrlich-Strasse 51-59, 63225 Langen, Germany. ||Corresponding author: A.D.M.E. Osterhaus, Institute of Virology, Erasmus University Rotterdam, PO Box 1738, 3000 DR Rotterdam, The Netherlands. (Received 6 December 1994; revised 13 March 1995; accepted 22 March 1995)
}

The envelope gene encoded surface (SU) and transmembrane (TM) glycoproteins of lentiviruses play a crucial role in virus attachment and fusion to host cells, and serve as targets for virus neutralizing (VN) antibodies and helper and cytotoxic $T$ cells (for review see Ref. 2). Therefore, the inclusion of these envelope glycoproteins in candidate vaccine preparations in a form that stimulates both cellular and humoral immunity is desirable.

In several studies SIV candidate vaccines have been tested for their ability to induce protective immunity against challenge with SIV. Although in many of these studies induction of protective immunity by candidate SIV vaccines was reported, it was shown that in most cases an anti-cell rather than an anti-virus response was at the basis of this protection ${ }^{3}$. We have shown that after vaccination with envelope glycoprotein enriched whole SIVmac, four of the eight vaccinated animals were protected against an intravenous challenge with SIVinfected peripheral blood mononuclear cells (PBMC) $)^{4.5}$. So far, in SIV experiments there has been only one report describing protection induced with a recombinant vaccine preparation ${ }^{6}$. In this study priming with live recombinant vaccinia virus expressing the envelope protein followed by boosting with recombinant envelope 
protein expressed by baculovirus, resulted in protection of rhesus macaques against a homologous challenge with a molecular clone of SIVmne. In the SIVmac model system, immunization with recombinant SIV preparations led to a reduced virus load ${ }^{7.8}$.

Successful vaccines against lentivirus infections should at least provide protective immunity against homologous viruses and related variants. This may be achieved by the induction of immune responses directed to conserved regions of the envelope protein involved in $\mathrm{VN}$, or by the simultaneous induction of immune responses to variable regions on the envelope protein of different variant viruses. In the present study, we describe the analysis of the antigenicity and immunogenicity of the envelope protein of SIVmac32H and its counterpart which had undergone an in vivo passage of 11 months. For this purpose, recombinant envelope proteins were obtained from PBMC of two monkeys shortly after infection with the respective viruses, to select for envelope sequences which are related to viruses which actually establish infection.

\section{MATERIALS AND METHODS}

\section{Virus}

SIV-env sequences were analyzed from two rhesus monkeys (Macaca mulatta), numbers 8672 and 8789 . These animals belonged to control groups of animals in a previous SIV vaccination study ${ }^{5}$. Macaque number 8789 had been inoculated intravenously with $10 \mathrm{MID}_{50}$ of the $32 \mathrm{H}$ isolate of SIVmac251 (11/88 pool) ${ }^{9,10}$. The monkey died from AIDS-like symptoms 26 weeks postinfection. Macaque number 8672 was inoculated intravenously with $10 \mathrm{MID}_{50}$ of SIV-infected PBMC derived from rhesus macaque number $1 \mathrm{XC}$. PBMC of number $1 \mathrm{XC}$ were isolated 11 months post-infection with an intravenous dose of $50 \mathrm{MID}_{50}$ of the $32 \mathrm{H}$ isolate of SIVmac251 (pool 11/88) ${ }^{11}$. Macaque number 8672 died from AIDS-like symptoms 39 weeks post-infection. PBMC were isolated from macaques numbers 8789 and 8672 two and four weeks post-infection, respectively, and used for sequence analysis. At these time points no SIVmac32H specific VN serum antibodies had developed in the respective monkeys ${ }^{5}$.

\section{DNA template preparation}

PBMC of rhesus macaques numbers 8789 and 8672 were resuspended in a buffer containing $50 \mathrm{mM} \mathrm{KCl}, 10$ $\mathrm{mM}$ Tris- $\mathrm{Cl}(\mathrm{pH}$ 8.4), $1.5 \mathrm{mM} \mathrm{MgCl}, 0.5 \%$ Tween-20 and $100 \mu \mathrm{g} \mathrm{ml}^{-1}$ proteinase $\mathrm{K}$ at a concentration of $1 \times 10^{7}$ cells $\mathrm{ml}^{-1}$ and incubated for $16 \mathrm{~h}$ at $54^{\circ} \mathrm{C}$, followed by $10 \mathrm{~min}$ at $95^{\circ} \mathrm{C}$. The resulting cell lysate was used as source of template DNA in subsequent PCR amplifications.

\section{PCR amplification}

As the number of infected cells in PBMC of SIVinfected macaques early in infection was expected to be low, a nested primer PCR was developed to obtain sufficient quantities of DNA for cloning. Primers for PCR were chosen which recognized conserved sequences flanking the SIVmac envelope gene sequence (Los Alamos AIDS database). Outer set of primers: $5^{\prime}-\mathrm{GGC}$
CAACCTGGGGGAGGAAATCC-3' (6398); 5'-GCA CTGTAATAATCCCTTCCAGTCCCCCC-3' (9481). Inner set of primers: 5'-CGCGTCGACGTAAGTAT GGATGTCTTGGGAATCAGC-3' (6599); 5'-GACCC CGGGCCCCTGATTGTATTTCTGTCCC-3' (9264). The positions of the $5^{\prime}$-nucleotide in the SIVmac32H-J5 molecular clone are indicated in parentheses. SmaI and Sall restriction sites (presented in bold) were incorporated near the $5^{\prime}$ ends of the inner primer set to facilitate subsequent cloning. These sites were chosen from a list of "non-cutters" generated after analysis of the SIVmac251 sequence. Ten micfolitres of the cell lysate were added to a PCR reaction mixture containing $10 \mathrm{mM}$ Tris-Cl (pH 8.4), $50 \mathrm{mM} \mathrm{KCl}, 1.5 \mathrm{mM} \mathrm{MgCl}_{2}, 200 \mu \mathrm{g}$ $\mathrm{ml}^{-1}$ gelatin, $200 \mu \mathrm{M}$ of each dATP, dCTP, dGTP and $\mathrm{dTTP}, 0.1 \mu \mathrm{M}$ of each primer of one primer set and 2.5 units Taq polymerase (AmpliTaq, Cetus, Emeryville, CA). The total reaction volume of $100 \mu \mathrm{l}$ was overlaid with mineral oil. DNA was amplified by a 4 min $94^{\circ} \mathrm{C}$ denaturation step followed by 36 cycles comprising denaturation at $94^{\circ} \mathrm{C}$ for $1 \mathrm{~min}$, annealing at $53^{\circ} \mathrm{C}$ for 1 min and extension at $72^{\circ} \mathrm{C}$ for $2 \mathrm{~min}$. Reamplification of $10 \mu \mathrm{l}$ of the first PCR was performed with the inner set of primers under the same reaction conditions for 40 cycles.

\section{Molecular cloning and sequence analysis}

PCR reaction mixtures were extracted once with phenol/chloroform and concentrated on an Amicon-30 filter (Amicon). DNA was subsequently analyzed on a $0.9 \%$ agarose gel, the presumed $2.6 \mathrm{~kb}$ envelope fragment was purified and digested with Sall and SmaI and cloned into SalI and SmaI digested cloning vector $\mathrm{pB}$ luescriptII SK(+) (Stratagene, La Jolla, CA). Sequencing was carried out using a multiwell microtitre plate DNA sequencing system (Amersham) based on the dideoxynucleotide chain termination sequence reaction. The nucleotide and protein alignments were determined with Lasergene software (DNAstar Inc., London, UK).

\section{Nucleotide sequence accession numbers}

Nucleotide sequences of clones 8672-20 and 8789-11 have been submitted to GenBank and are available under accession numbers L35596 and L35597, respectively.

\section{In vitro mutagenesis}

In order to mutate the presumed primary and secondary cleavage site of the precursor envelope protein ${ }^{12}$, amino acid substitutions were made by site-directed mutagenesis (primary cleavage site: RNKR to RNSA; secondary cleavage site: $\mathrm{KR}$ to $\mathrm{KS}$ ) using three $P C R$ reactions. The $\mathrm{pBS}^{+}$constructs containing the respective envelope genes were used as template DNA. Primers $5^{\prime}$-mut (5'-GTGAAGAGcTACACTA CTGGTGGCACCTCAAGAAATAgcgcAGGGG TCT TTGTGC (8135)) and 3'-NcoI (5'-GCATTTGGCCAT GGTACAGTAGTGTGGC-3' (8478)) were used to obtain fragment $5^{\prime}$-mut $/ 3^{\prime}-\mathrm{NcoI}$. Using primer pair $3^{\prime}$-mut (5'-GCACAAAGACCCCTgcgcTATTTCTTG AGGTG CCACCAGTAGTGTAgCTCTTCAC-3', reverse complementary to $5^{\prime}$-mut) and $5^{\prime}$-ClaI (5'-GGCAGAAC 
TATCGATTGGAATTGGG-3' (8059)) fragment 5-'ClaI/ $3^{\prime}$-mut was obtained. The positions of the $5^{\prime}$-nucleotide in the SIVmac32H (J5) sequence are indicated in parentheses. The lower case letters represent nucleotide changes that were introduced. Subsequently, the $5^{\prime}-\mathrm{Cla} / 3^{\prime}$-mut and $5^{\prime}$ mut $/ 3^{\prime}$-NcoI fragments were used as template in a PCR using primers 5'-ClaI and $3^{\prime}-\mathrm{N}$ coI. The PCR-derived 5'ClaI/3'-Ncol fragment including the nucleotide substitutions was purified by preparative gel electrophoresis, digested with ClaI and Ncol and cloned into ClaI and NcoI digested clones 8672-20 and 8789-11, respectively. The presence of the substitutions was confirmed by sequence analysis. The mutated envelope proteins were designated $8672-\mathrm{m}$ and $8789-\mathrm{m}$, respectively.

\section{Construction of recombinant vaccinia viruses}

Both the wild-type and the mutated 8672-20 and 8789-11 envelope genes were cloned under control of a synthetic early/late vaccinia promoter in the plasmid vector pSC65. Recombinant viruses were made by homologous recombination with vaccinia virus (WR strain) as previously described ${ }^{13}$. A control recombinant vaccinia virus, vSC65, was made by homologous recombination of the plasmid vector pSC65 with no insert ${ }^{14}$. Recombinant vaccinia viruses were plaque purified at least three times and virus stocks were grown on RK13 cells.

\section{Production of recombinant $e n v$ glycoproteins}

Baby hamster kidney (BHK) cells were infected with recombinant vaccinia virus (rVV) at a multiplicity of infection of 4 and incubated for $20 \mathrm{~h}$. Cells were collected and the vaccinia virus was inactivated in $1.5 \%$ paraformaldehyde for $30 \mathrm{~min}$. Subsequently, cells were incubated in $0.2 \mathrm{M}$ glycine for $1 \mathrm{~h}$. Membrane proteins were solubilized in TN $(10 \mathrm{mM}$ Tris $-\mathrm{HCl}$ pH 7.4, 0.15 $\mathrm{M} \mathrm{NaCl}$ ) containing 4\% RBT (n-octylpolyoxyethylene, Rosenbuch-Tenside; Bachem, Bubendorf, Switzerland) at a concentration of $2 \times 10^{7}$ cells $\mathrm{ml}^{-1}$ for $90 \mathrm{~min}$ at $4^{\circ} \mathrm{C}$. The cell lysate was centrifugated for $15 \mathrm{~min}$ at 2500 revs $\mathrm{min}^{-1}$. Glycoproteins were allowed to adsorb to lentil lectin sepharose (Pharmacia LKB, Uppsala, Sweden) overnight. Subsequently, the lentil lectin sepharose was washed with buffer A (10 mM Tris- $\mathrm{HCl}$ pH 7.4/0.3 M $\mathrm{NaCl} / 0.5 \% \mathrm{RBT}$ ) followed by washing with buffer $\mathrm{B}$ (buffer A supplemented with $10 \mu \mathrm{g} \mathrm{m}^{-1}$ of the lipids cholesterol and phosphatidylcholine (Sigma, St. Louis, USA)). Bound glycoproteins were eluted with buffer $\mathrm{C}$ (buffer B containing $0.5 \mathrm{M}$ a-methylmannopyranoside). Quantification of SIV-envelope glycoproteins was performed as described previously ${ }^{5}$.

\section{Formulation of antigen preparations and immunization schedule in rats}

For the preparation of immune-stimulating complexes (iscoms) lentil lectin enriched $8672-\mathrm{m}$ or $8789-\mathrm{m}$ proteins were mixed with the lipids cholesterol and phosphatidylcholine (Sigma; stock $10 \mathrm{mg} \mathrm{ml}^{-1}$ in $10 \%$ MEGA-10 (Boehringer Mannheim, Mannheim, Germany)) and Quil A (Spikoside, Iscotec, Luleå, Sweden) at a ratio of 1:1:5(w/w/w). After ultrasonic treatment for $10 \mathrm{~min}$ the mixture was incubated for $1 \mathrm{~h}$ at room temperature
(RT). Subsequently, the mixture was extensively dialysed against $10 \mathrm{mM}$ Tris- $\mathrm{HCl} \mathrm{pH} 7.4 / 0.3 \mathrm{M} \mathrm{NaCl}$, layered over a linear $(10-60 \%)$ sucrose gradient and centrifugated $\left(18 \mathrm{~h}\right.$ at 25000 revs $\mathrm{min}^{-1}$ : Beckmann SW28 rotor). The gradient was fractionated and fractions were analyzed for the presence of envelope protein by enzyme-linked immunosorbent assay (EIISA). Fractions containing peak levels of the envelope protein (coinciding with the presence of iscom-like structures, as judged by electron microscopy) were pooled.

For the Quil A and MDP-tsl antigen preparations, $3 \mu \mathrm{g}$ of lentil lectin enriched SIV-env 8789-m was adjuvanted either with $10 \mu \mathrm{g}$ Quil A (Spikoside, Iscotec) or $0.5 \mathrm{ml}$ MDP-tsl $(0.462 \mathrm{ml}$ PBS containing $12.5 \mu \mathrm{g}$ MDP (muramyl dipeptide) (Sigma), $1 \mu 1$ Tween-80, $25 \mu 1$ squalene and $12.5 \mu \mathrm{l}$ of the plutonic block polymer L101 (Serva, Heidelberg, Germany)) ${ }^{15.16}$.

Female rats (RIV:tox) were divided into groups of four animals and were immunized intramuscularly (i.m.) with the different antigen preparations and boosted four weeks later with the same material. Each rat received $3 \mu \mathrm{g}$ of rgp 160 per immunization except for the rats immunized with both $8672-\mathrm{m}$ and $8789-\mathrm{m}$ incorporated into iscoms. These received $3 \mu \mathrm{g}$ of each rgpl60 construct per immunization. Serum samples were collected before and $2,4,5,6,8$, and 14 weeks after the first immunization.

\section{Western blotting}

Procedures for western blotting were performed as described previously ${ }^{5}$.

\section{Binding of monoclonal antibodies (Moabs) to different SIV-envelope preparations}

Multiwell plates (Costar, Cambridge, USA) were coated with $100 \mu \mathrm{l}$ PBS containing $200 \mu \mathrm{g}$ ConA and then incubated with the different SIV-envelope preparations at a concentration of $10 \mathrm{ng}$ envelope protein in $100 \mu \mathrm{l}$ PBS containing $1 \% \mathrm{RBT}$, for $16 \mathrm{~h}$ at RT. Wells were blocked with PBS containing $0.1 \%$ Tween- 20 and $1 \%$ BSA (PTB) supplemented with $10 \%$ FCS, and subsequently incubated for $2 \mathrm{~h}$ at $\mathrm{RT}$ with threefold serial dilutions starting at 1:200 of one of the env-specific Moabs (ascitic fluid, kindly provided by Dr K. Kent). Plates were washed and incubated with biotin conjugated goat-anti-mouse IgG (Amersham) and horse radish peroxidase (HRPO) conjugated streptavidine (Amersham). The substrate reaction was carried out with $3,3^{\prime}, 5,5^{\prime}$-tetramethyl-benzidine ${ }^{17}$. The antibody titre was defined as the reciprocal of the dilution of the Moab giving $50 \%$ of the maximum O.D. 450 obtained for that Moab and was determined from three independent experiments. Values two times that of similarly processed preparations of vSC65-infected BHK cells were considered positive.

\section{Whole SIV ELISA to demonstrate envelope-specific antibodies}

ConA coated multiwell plates were incubated with $50 \mu 1$ of SIV-infected C8166 cell lysate 5 in PBS/1\% triton 
containing $70 \mathrm{ng} \mathrm{ml}^{-1}$ SIV-env, for $16 \mathrm{~h}$ at RT. (Quantification of the SIV-envelope protein was performed as described previously ${ }^{5}$.) Wells were blocked with PTB containing $10 \%$ FCS and subsequently incubated with $50 \mu 1$ of twofold dilutions of rat serum in PTB containing 4\% FCS. After $2 \mathrm{~h}$ incubation at RT, wells were washed and bound antibody was detected using a rabbitanti-rat Ig-HRPO antibody preparation (DAKO, Glostrup, Denmark). The substrate reaction was carried out as described above. Endpoint titres were calculated using a cut-off value twofold above the respective dilution of the pre-immune serum at O.D. ${ }_{450}$. Antibodies with specificity for BHK cell components in the immunogen did not react with plate bound C8166 cell components. Comparison of titres between groups was conducted using a one-way analysis of variance (Anova; Minitab Inc., State college, USA). Titres were considered significantly different if $p<0.05$.

\section{SIV-envelope specific Moab inhibition ELISAs}

Inhibition ELISAs were carried out as described previously ${ }^{5}$ with minor modifications. Briefly, ConA coated multiwell plates were incubated with $100 \mu \mathrm{l} \mathrm{C8166-SIV}$ cell lysate containing $70 \mathrm{ng} \mathrm{ml}^{-1} \mathrm{SIV}$-envelope proteins. One hundred microlitres of twofold dilutions of rat serum were incubated for $1 \mathrm{~h}$ at RT. Subsequently, $50 \mu \mathrm{l}$ was taken out and wells were supplemented with $50 \mu 1$ of Moab in PTB containing 4\% FCS. Only Moabs with VN activity were used for these inhibition studies. It has been shown that Moabs KK5 and KK9 of competition group 1, which recognize a conformation dependent epitope, do not interfere with the binding of the SIV envelope protein to SCD4 as demonstrated in immunoprecipitation assays ${ }^{18.31}$. The Moabs were diluted to give an absorbance at O.D. ${ }_{450}$ of $50-70 \%$ of the maximum absorbance in an indirect SIV-ELISA. Plates were incubated with a biotin-conjugated goat-anti-mouse $\mathrm{IgG}$ antibody preparation (Amersham) in PTB containing $4 \%$ FCS and 5\% normal rat serum (NRS), which was pre-incubated in this buffer for $1 \mathrm{~h}$ at RT, and subsequently with HRPO conjugated streptavidine (Amersham). The anti-mouse biotin IgG antibody preparation did not cross-react with rat Ig in this assay. Inhibition titres were defined as the dilution of rat serum inhibiting $50 \%$ of the absorbance measured without competing antibody. The difference in titre between the different immunization groups was evaluated through a student's $t$-test. Differences of $p<0.05$ were considered significant.

\section{SIV neutralization assay}

The SIV neutralization assay using SIVmac32H was performed as described previously ${ }^{5}$. Briefly, $10 \mu \mathrm{l}$ of different dilutions of heat inactivated sera were incubated (four replicates per dilution) with $10 \mu \mathrm{l}$ of SIVmac32H diluted to give ten infectious particles per $10 \mu \mathrm{l}$. After $30 \mathrm{~min}$ incubation at $37^{\circ} \mathrm{C}, 200 \mu \mathrm{l}$ of media containing $2000 \mathrm{C} 8166$ cells was added to each well of the microtitre plate. Plates were incubated for seven days at $37^{\circ} \mathrm{C}$ after which cells from each well were transferred to poly-L-lysine coated flat bottom microtitre plates, fixed in methanol, and examined for the presence of SIVmac-infected cells using a SIV-specific immuno- peroxidase assay. Wells containing no infected cells were scored as negative and the number of negative wells was used to determine the neutralizing dose $50 \%$ end-point $\left(\mathrm{ND}_{50}\right)$ for that serum by the method of SpearmannKarber. The difference in titre between the different immunization groups was evaluated through a student's $t$-test. Differences of $p<0.05$ were considered significant.

\section{RESULTS}

\section{Selection of SIV-envelope glycoproteins and sequence comparison}

PBMC were collected from two rhesus macaques, two weeks (monkey number 8789 ) or four weeks (monkey number 8672 ) after infection with SIVmac32H. The first animal had been infected with $10 \mathrm{MID}_{50}$ of the cell-free virus (11/88 pool) and the second with 10 MID $_{50}$ of the PBMC from a monkey 11 months after infection with the 11/88 pool $^{5}$. Representative SIV envelope genes were derived from the respective monkeys. SIV envelope clone 8789-11 was selected with a sequence shared by five of six clones in the variable regions 1 and 2 (V1 and V2) $)^{19}$ and clone 8672-20 was selected from a panel of three clones which showed considerable similarities in this region with the exception of single amino acid differences. The predicted amino acid sequences of clones $8672-20$ and $8789-11$ are outlined in Figure 1, where they are compared with that of the consensus sequence of the envelope glycoprotein present in the $11 / 88$ stock of the $32 \mathrm{H}$ isolate of SIVmac251 as identified by Almond et al. ${ }^{19}$ As expected the 8789-11 sequence showed much more similarity to the consensus sequence of the envelope glycoprotein present in the $32 \mathrm{H}$ isolate than the $8672-20$ sequence ( 3 and 19 amino acid differences, respectively). A $98 \%$ overall amino acid sequence identity was shown between clones $8672-20$ and 8789-11. Most strikingly, in the V1 region of the 8672-20 envelope sequence an extended sequence was found that was rich in serine and threonine residues, leading to a sequence commonly found in heavily O-linked glycosylated proteins ${ }^{20}$. An extra potential $\mathrm{N}$-linked glycosylation site was found in clone 8672-20 directly $\mathrm{N}$-terminal of the start of the V1 region. In addition. two amino acid differences were found in the $\mathrm{V} 2$ region, one in the $\mathrm{V} 4$ region, four amino acid differences outside the variable regions of the SU and five in the TM part of the SIV-envelope precursor sequence (Figure 1).

\section{Expression of SIV-envelope glycoproteins by rVVS}

The RNKR sequence in clones 8672-20 and 8789-11, representing the cleavage site between the SU and TM part of the envelope genes, together with a second conserved cluster of basic amino acids which may serve as a secondary cleavage site $^{12}$, was modified by site-directed mutagenesis. Subsequently, rVVs were generated from the parental $8672-20$ and 8789-11 envelope genes (designated v8672 and v8789, respectively) and from the cleavage site mutated envelope genes (designated $\mathrm{v} 8672-\mathrm{m}$ and $\mathrm{v} 8789-\mathrm{m}$, respectively).

Western blot analysis of BHK cells infected with v8672 using a TM-specific Moab, revealed protcins with 
1

consensus MGCLGNQLLIAILLLSVYGI YCTQYVTVFYGVPAWRNATI PLFCATKNRDTWGTTQCLBD. NGDYSELALNVTESFDAWEN TVTEQAIEDV 8789-11 _.

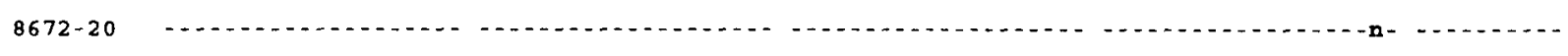
$91 \quad \mathrm{~V}_{2}$ consensus WQLFETSIKPCVKLSPLCIT MRCNRSETDKWGLTKSLTTT APT . . APTAASKIDMVNET SSCITHDNCTGLEQEQMIGC KFNATGLKRD 8789-11

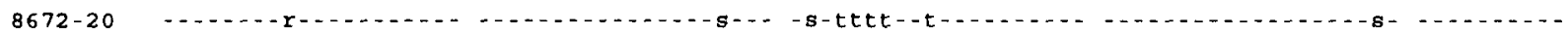
$\begin{array}{lll}181 & V 2 & 270\end{array}$

CONEENSUS KTKEYNETWYSTDLVCEOGN STDNESRCYMNHCKTSVIQE SCDKHYWDTIRFRYCAPPGY ALLRCNDTNYSGFMPKCSKV VVSSCTRMME

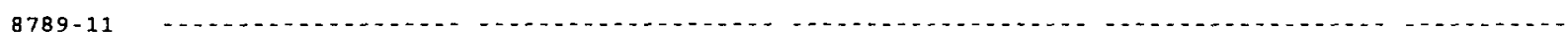

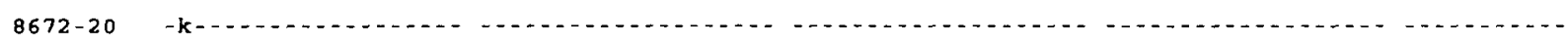
$271 \quad 360$ Consensus TQTSTWFGFNGTRAENRTY Y YWHGRDNRTIISLNKYYNLT MKCRRPGNKTVLPVTIMSGL VFHSQPINDRPKQAWCWFGG KWKDAIKEVK 8789-11

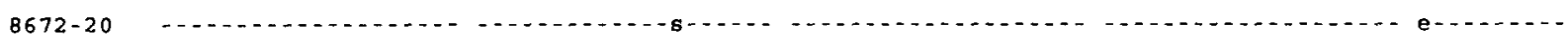

Consensus QTIVKHPRYTGTNNTDKINL TAPGGGDPEVTFMWTNCRGE FLYCKMNWFLNWVEDRNTTN QKPKEQHKRNYVPCHIRQII NTWHKVGKNV 8789-11

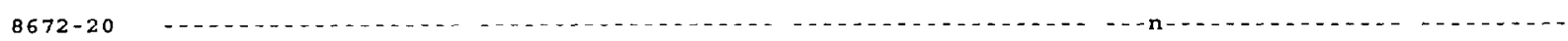
V5 SU/TM 540 Consensus YLPPREGDLTCNSTVTSLIA NIDWTDGNOTNITMSAEVAE LYRLELGDYKLVEITPIGLA PTDVKRYTTGGTSRNKRGVF VLGFLGFLAT $8789-11$ -

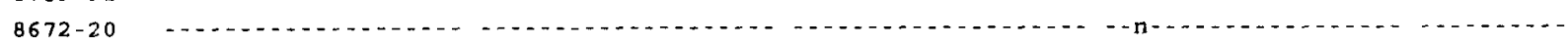

Consensus AGSAMGAASLTLTAQSRTLL AGIVQQQQQLLDVVKRQOEL LRLTVWGTKNLOTRVTAIEK YLKDQAQLNAWGCAFRQVCH TTVPWPNASL 8789-11

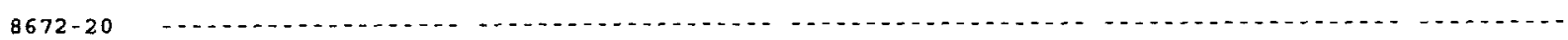
631

COnSENSUS TPNWNNDTWQEWERKVDFLE ENITALLEEAQIQOEKNMYE LQKLNSWDVFGNWFDLASWI KYIQYGIYIVVGVILLRIV IYIVQMLAKLR 8789-11 -

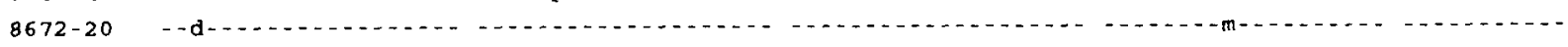

721810

consensUS QGYRPVFSSPPSYFQQTHIQ QDPALPTREGKEGDGGESGG NSSWPWQIEYIHFLIRQLIR LLTWLFSNCRTLLSRAYQIL QPILQRLSAA

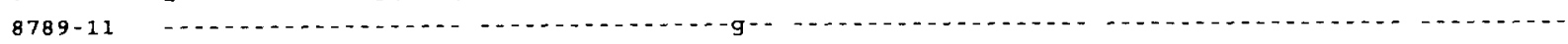

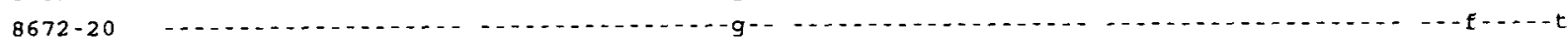
811

consensuS LQRIREVLRTELTYLQYGWS YFQEAVQVGWRSATETLAGA WGDLWETLRRGGRWILAIPR RIRQGLELTLI

8789-11 _.

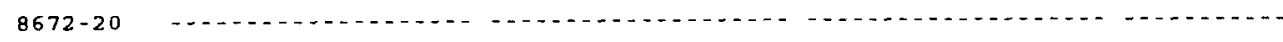

Figure 1 Predicted amino acid sequences of the envelope precursor protein of clones $8672-20$ and $8789-11$. They are aligned with the consensus sequence for the envelope glycoprotein present in the $32 \mathrm{H}$-isolate of SIVmac251 (11/88 pool) as identified by Almond et al. ${ }^{17}$ A dash indicates that the amino acid is identical to the consensus sequence; variation in sequence is given in single letter code. Amino acid positions where no equivalent is present are indicated by a dot. The regions of the envelope protein equivalent to the variable regions (V) of HIV-1 are indicated $^{34}$. The predicted cleavage site between the SU and TM part of the envelope protein is indicated. Potential N-linked glycosylation sites $(\mathrm{N}-\mathrm{X}-\mathrm{S}$ or $\mathrm{N}-\mathrm{X}-\mathrm{T})$ are indicated in bold type

molecular sizes of 160 and $41 \mathrm{kDa}$ (Figure $2 B$, lane 2). The $160 \mathrm{kDa}$ protein was also recognized by the SU membrane specific Moab (Figure 2A, lane 2). In the culture medium a protein with a $\mathrm{Mr}$ of about $120 \mathrm{kDa}$ was recognized by the gp120-specific Moab (Figure 2A). These data indicate that, like in the native protein, a $160 \mathrm{kDa}$ SIV precursor protein is synthesized which is processed to a $41 \mathrm{kDa}$ TM protein and a $120 \mathrm{kDa} \mathrm{SU}$ protein which is also released into the medium. In v8789-infected BHK cells the $160 \mathrm{kDa}$ envelope precursor protein was predominant. In the culture medium the SU envelope glycoprotein was detectable. In the culture medium of cells infected with v8672-m and $\mathrm{v} 8789-\mathrm{m}$ containing the mutated envelope genes, no indication for the presence of the SU envelope glycoprotein was found.

Incorporation studies with lentil lectin purified extracts from BHK cells infected with either of the rVVs, showed that iscoms prepared with the cleavage site mutated recombinant envelope proteins contained the gp160 precursor protein (Figure 3).

\section{Antigenicity of recombinant envelope glycoproteins $8672,8672-\mathrm{m}, 8789,8789-\mathrm{m}$ and envelope glycoprotein derived from SIVmac32H}

Antigenicity of the envelope proteins expressed by $\mathrm{v} 8672$, v8672-m, v8789 and v8789-m incorporated into iscoms was assessed with a panel of 15 SIV-envelope specific Moabs divided over seven competition groups $^{21.22}$ (see Figure 4). The antibody titre at which $50 \%$ of the maximum O.D. 450 was obtained, was similar for all Moabs tested comparing the envelope glycoproteins derived from SIVmac32H-infected C8166 cells and rVV 8789 expressed envelope glycoprotein. Envelope glycoproteins derived from v8672 were poorly recognized by Moabs of competition group 1 compared to envelope glycoproteins derived from v8789 or SIV itself. 


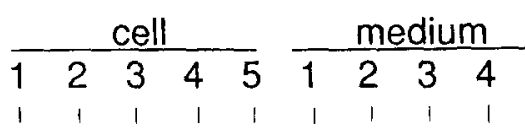

A.

Figure 2 Western blot analysis of wild-type and mutant SIV envelope glycoproteins expressed by rVV in BHK cells using a gp120-specific monoclonal antibody (KK10) (A) or a gp41-specific monoclonal antibody (KK20) (B) with cell lysate (cell) and culture medium (medium). Lane 1, vSC65 (negative control); lane 2, v8672; lane 3, v8672-m; lane 4, v8789; lane 5, v8789-m. The locations of the envelope precursor protein (pre), surface membrane protein (su) and transmembrane protein (tm), as well as the mobilities of molecular weight markers, are indicated

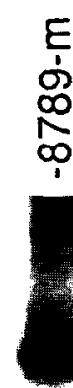

MW

(kd)

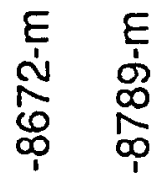

$-200-$

-116 -

- 97 -

-66 -

$-45-$
$-45$

\section{- PRE}

\section{PRE}

$-116$

- 97 -

$-66-$

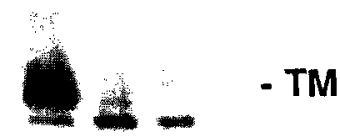

B. recognized the $8789-\mathrm{m}$ envelope protein. shown).

No differences were found in the binding of the Moabs to the 8672 and 8789 envelope proteins in their native or cleavage site mutated form, except for one of the Moabs of competition group 7, KK16, which hardly

No changes in binding of the Moabs to the recombinant envelope glycoproteins were found as a consequence of either paraformaldehyde fixation, lentil-lectin purification, or incorporation into iscoms (data not

\section{Immunogenicity of recombinant envelope glycoproteins 8672-m and 8789-m}

The immunogenicity of the $8672-\mathrm{m}$ and $8789-\mathrm{m}$ envelope glycoproteins incorporated into iscoms was analyzed by immunizing laboratory rats. The overall kinetics and levels of SIV-specific antibody titres induced by immunization with two times $3 \mu \mathrm{g}$ of one of the envelope glycoproteins proved to be similar when measured by a whole SIV ELISA. Rats immunized with both iscom preparations $(3 \mu \mathrm{g}$ envelope protein of each per immunization) showed a significantly higher antibody response (Figure 5A). Inhibition of the Moab KK56 could only be clearly demonstrated with sera from rats immunized with 8789-m envelope glycoproteins (Figure $5 B$ ). This inhibition pattern of KK 56 was representative of all Moabs of competition group 1 (data not shown). Apparently there is a direct relationship between the recognition or presence of certain epitopes and their capacity to induce specific antibodies. VN serum antibody titres of $8789-\mathrm{m}$ iscom immunized rats were also significantly higher than those of $8672-\mathrm{m}$ iscom immunized animals (Figure $5 \mathrm{C}$ ). Similar levels of VN serum antibodies and K K56 inhibition titre were found in rats 


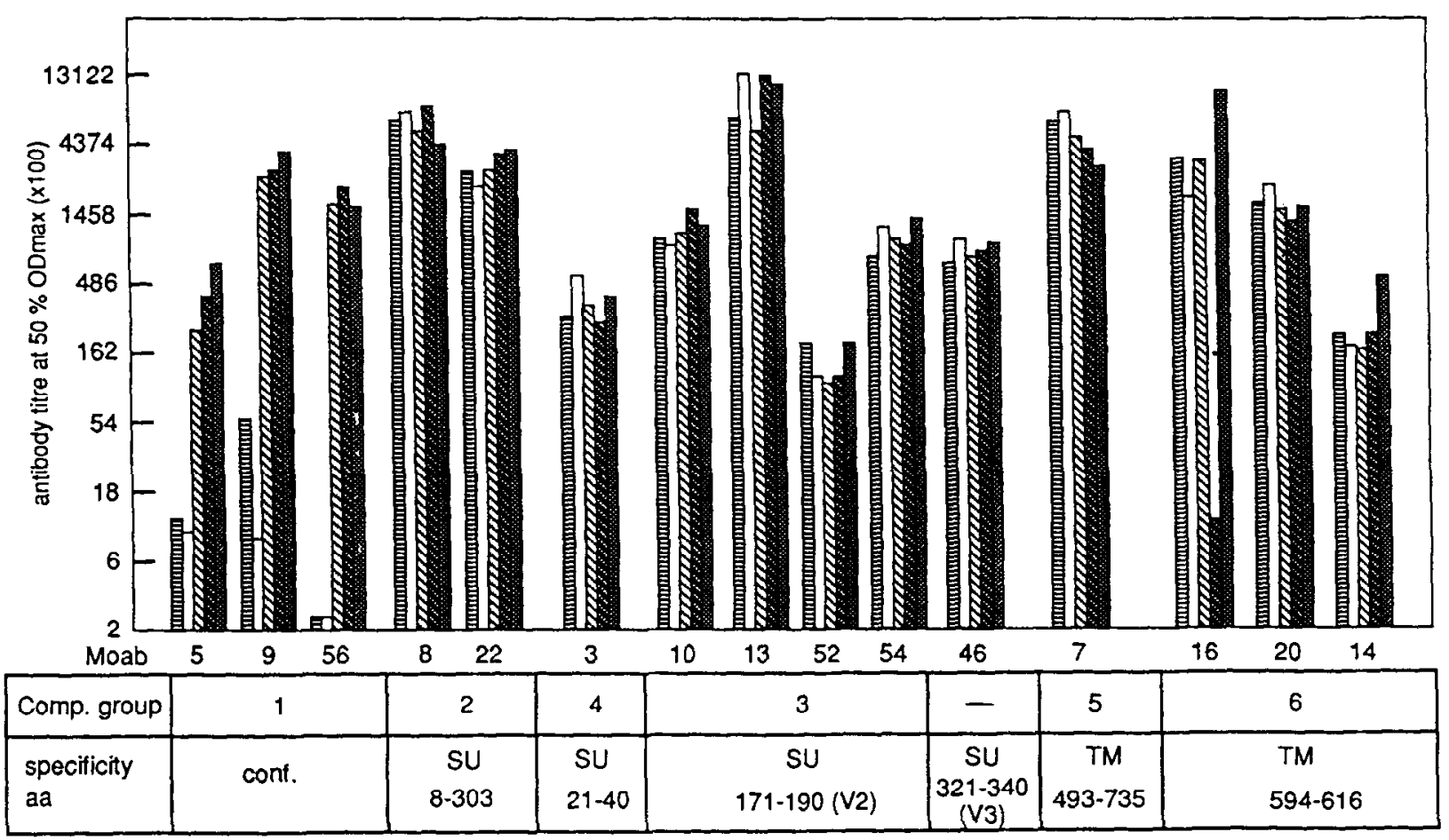

Figure 4 Binding of 15 SIV-envelope-specific monoclonal antibodies to the $8672,8672-\mathrm{m}, 8789$ and $8789-\mathrm{m}$ envelope glycoproteins incorporated into iscoms and SIVmac251 $(32 \mathrm{H})$ produced envelope proteins on $\mathrm{C} 8166 \mathrm{cell}^{5}$. Competition groups are defined in Kent et al. ${ }^{19,20}$ aa; amino acid numbers BK28 SIV-envelope protein. Conf.; conformational epitope. Bars represent the dilution of the monoclonal antibody giving $50 \%$ of the maximum O.D. 450 obtained using that monoclonal antibody. $\boxminus=8672, \square=8672-\mathrm{m}$, 图 $=8789, \square=8789-\mathrm{m}$, 胫 $=\mathrm{C} 8166-\mathrm{SIV}$

immunized with the $8789-\mathrm{m}$ envelope proteins alone or in combination with the $8672-\mathrm{m}$ envelope protein (Figure $5 B, C$ ).

\section{Immunogenicity of SIV-envelope glycoprotein 8789-m presented in the context of different adjuvant systems}

The effect of different adjuvant systems on the immunogenicity of the $8789-\mathrm{m}$ envelope glycoprotein was studied by immunizing rats twice with $3 \mu \mathrm{g}$ of this protein using Quil A, MDP-tsl or iscoms as adjuvant systems. Only rats immunized with envelope proteins adjuvanted with MDP-tsl showed a detectable antibody response after one immunization. After boosting, the highest envelope antibody titres measured by ELISA were seen with sera from rats immunized with the 8789-m envelope glycoprotein incorporated into iscoms $(p=0.07$. Figure $6 \mathrm{~A})$. There proved to be little decrease in serum antibody titres during the observation period, irrespective of the adjuvant used. The KK56 antibody inhibition titre as well as the VN serum antibody titre of rats immunized with the iscom-adjuvanted envelope glycoprotein were higher than those of rats immunized with envelope protein adjuvanted with Quil A or MDP-tsl, although only the difference in KK56 inhibition titres between sera from rats immunized with iscom and MDP-tsl adjuvanted glycoproteins proved to be significant (Figure 6B,C).

\section{DISCUSSION}

In the present study, we have shown that the antigenicity and immunogenicity of two envelope glycoproteins derived from the same parent virus, SIVmac32H, with different in vivo passage histories differed considerably: the envelope protein derived from PBMC of a monkey infected with a virus which had undergone an extra in vivo passage for 11 months was not recognized by a group of $\mathrm{VN}$ antibodies able to bind to the envelope protein of the parent virus, SIVmac $32 \mathrm{H}$. Upon immunization, this envelope protein failed to induce antibodies which could compete with these monoclonal antibodies for binding to the envelope protein of SIVmac32H. Concurrently, a lower total VN antibody titre against SIVmac32H was induced in comparison to that induced by the envelope protein derived directly from a SIVmac $32 \mathrm{H}$-infected monkey.

There are several indications that conformational epitopes are involved in eliciting SIV-neutralizing antibodies. SIV synthetic peptides proved to be poor inducers of VN antibodies, whereas immunization of macaques with recombinant envelope protein $\mathrm{gp} 110$ elicited strong VN antibodies ${ }^{23}$. Furthermore, VN activity in sera from infected macaques could be absorbed out with native $\mathrm{gp} 110$, but not with reduced or denatured gp110 $10^{23}$. Therefore, we chose the eukaryotic rVV expression system for the production of SIVenvelope glycoproteins to be incorporated in SIV candidate vaccines. Vaccinia virus infectivity was eliminated by paraformaldehyde treatment. Although paraformaldehyde is able to alter the antigenic structure of membrane proteins ${ }^{24}$, no differences in antigenicity were found in the SIV-envelope protein before and after paraformaldehyde fixation (Hulskotte et al., manuscript in preparation). The SIV $160 \mathrm{kDa}$ envelope precursor proteins, expressed by rVV v8672 and $v 8789$, were similarly cleaved to a $120 \mathrm{kDa}$ SU and $41 \mathrm{kDa} T M$ protein as in SIV-infected cells, although cleavage of especially 8789-env proved to be less efficient. No 

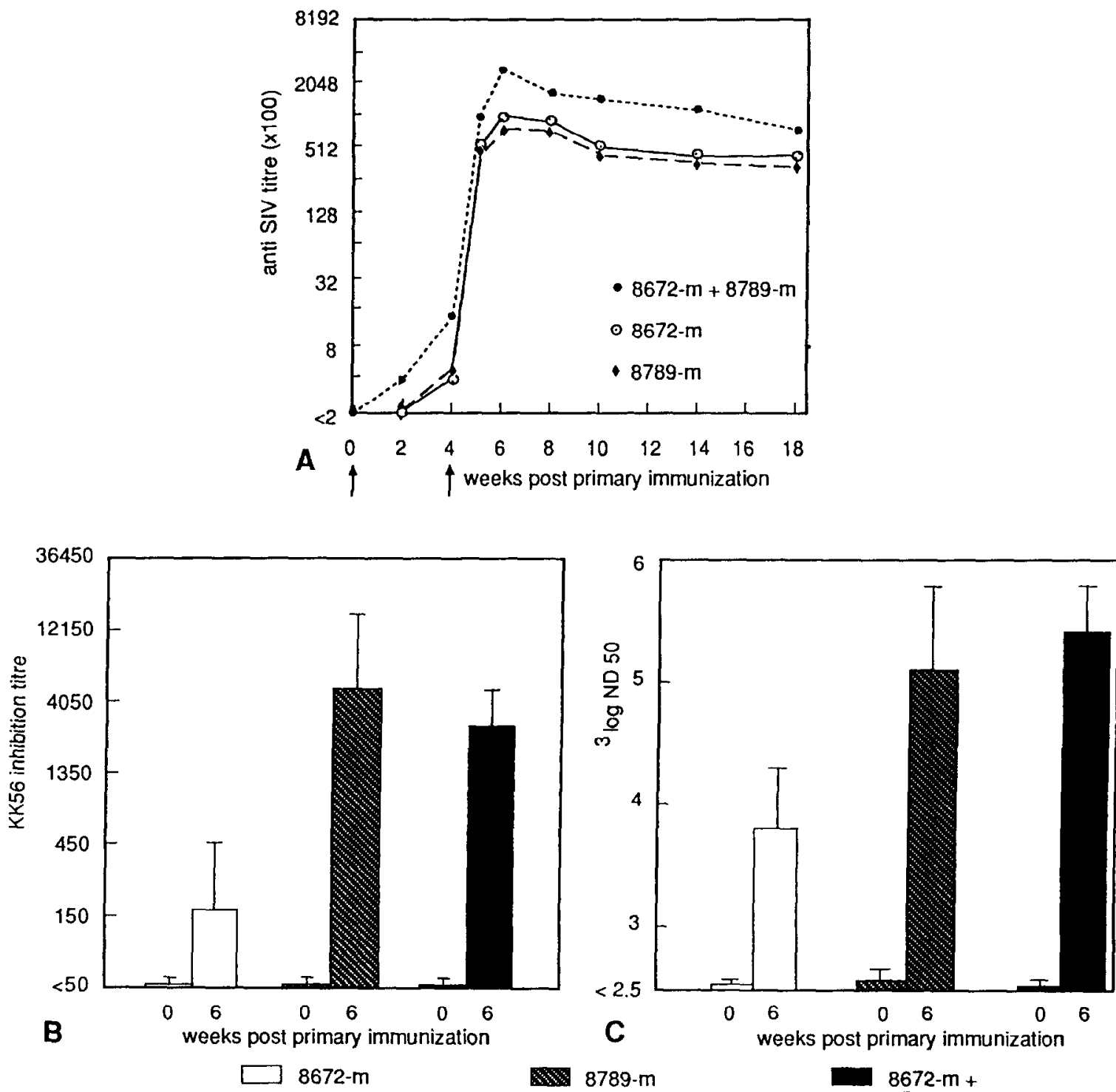

8789-m

$8672-m+$

8789-m

Figure 5 SIV envelope antibody development in rats immunized with $8672-\mathrm{m}$ iscoms ( $3 \mu \mathrm{g}$ per immunization), $8789-\mathrm{m}$ iscoms ( $3 \mu \mathrm{g}$ per immunization) or both ( $3 \mu \mathrm{g}$ each per immunization). Mean titres were calculated from four rats immunized with the same envelope preparation. A. Anti-SIV antibody titre. Weeks of immunization are indicated by arrows. B. Response to a conformational epitope before immunization and at peak level of antibody response (week 6 post primary immunization) as measured by inhibition of binding of monoclonal antibody KK56. The standard error of the means are presented as a vertical line. C. SIV-VN antibody titres before immunization and at peak level of antibody response (week 6 post primary immunization). Serial dilutions of monkey plasma were incubated with SIVmac $32 \mathrm{H}$ for 30 min at $37^{\circ} \mathrm{C}$. Subsequently, C8166 cells were added. The number of negative wells was used to determine the neutralizing $50 \%$ endpoint ( $\left.\mathrm{ND}_{50}\right)$ for the relative serum. The standard error of the means are presented as a vertical line

differences in antibody reactivities of a panel of 15 Moabs with envelope glycoproteins derived from SIVmac32H-infected C8166 cells and v8789 expressed envelope glycoprotein were found indicating that the rVV expression system is able to produce SIV-envelope glycoproteins in their native conformation.

Comparison of the amino acid sequences of $8672-20$ and 8789-11 envelope precursor proteins revealed a $98 \%$ amino acid similarity. It is interesting to note that in the V1 region of the 8672-20 sequence-derived from the in vivo passaged SIV - a T-rich stretch was inserted compared to the 8789-11 sequence. In SIVmne such a T-rich stretch was observed to be more common late in infection $^{25.26}$. Sequential sequence analysis of the envelope genes derived from these monkeys provided strong evidence that such T-rich stretches emerge later in infection by active selection, indicating expression in vivo ${ }^{26}$. The presence of this T-rich sequence in the envelope protein derived from PBMC of a monkey four weeks postinfection with an in vivo passaged virus indicates that sequence variation has most likely occurred during the 11 months of in vivo passage of SIVmac32H in monkey $1 X C$. In addition, at four weeks post-infection a homogenous population of envelope sequences has been demonstrated in both HIV and SIV infection ${ }^{27-30}$.

The 8672 envelope glycoprotein was poorly recognized by all VN Moabs directed to a conformation dependent epitope on the surface protein (KK5, KK9, $\mathrm{KK} 56$ ). A recent study suggests that the $\mathrm{V} 4$ region is involved in the recognition of the SIVmac239 envelope protein by Moabs KK5 and KK9, as demonstrated by an amino acid substitution at position 419 (equivalent position in SIVmac32H sequence, Figure 1), or deletions of four amino acids (position $421-424$ and 

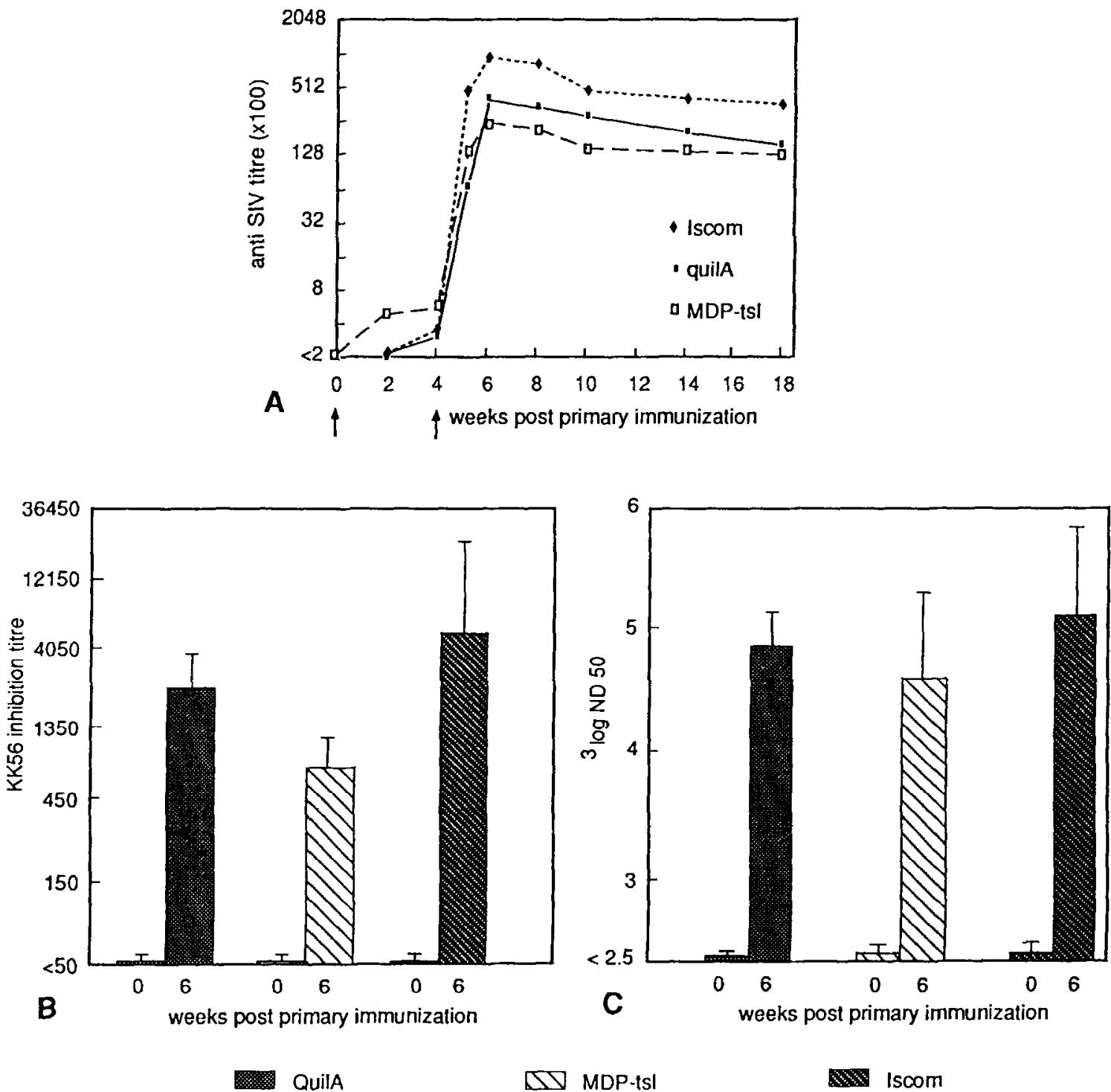

Figure 6 SIV-envelope antibody development in rats immunized with 8789-m envelope glycoproteins using different adjuvant systems. Mean titres were calculated from four rats immunized with the same adjuvant. Legends to Figure $6 A, B$ and $C$ are as for Figure $5 A, B$ and $C$, respectively

position 423-427) in this region ${ }^{31}$. We also found a difference in the amino acid sequence between the 8789 and 8672 envelope proteins in the same region in which the deletions were made ${ }^{31}$ ( $\mathrm{K}$ to $\mathrm{N}$ at position 423 ). However, a possible role for the other amino acid differences found between clone 8672 and 8789 in the recognition by the respective Moabs cannot be excluded and may be implicated in an escape mechanism from neutralization by antibodies which had developed in the macaque which donated the challenge material for monkey number 8672 .

No difference between the two envelope proteins was observed in binding of the other Moabs, including the VN antibodies KK10 and KK54 ${ }^{21,22}$. However, in contrast to the VN antibodies of competition group 1, binding of the VN Moabs KK10 and KK54 could neither be inhibited by the respective rat sera, nor by sera from monkeys immunized with the envelope glycoproteins $8672-\mathrm{m}$ and $8789-\mathrm{m}$ incorporated into iscoms, nor by sera from SIVmac-infected monkeys (data not shown). However, it has been shown by others that sera from some SIVmac-infected macaques ${ }^{32,33}$ and some macaques immunized with virus-derived gpl30 in incomplete Freund's adjuvant with or without prior priming with live rVV expressing the SIVmacBK28 envelope protein, react with the peptide epitopes of these Moabs $^{33}$.

To facilitate incorporation of the hydrophilic SU protein into iscoms, cleavage site mutated envelope proteins were expressed by rVVs. As mentioned above, the 8789 envelope glycoprotein was inefficiently cleaved exhibiting most of the envelope glycoprotein as the uncleaved precursor. However, we decided to also mutate this construct to obtain a uniform and well defined product. Indeed, the cleavage site mutated envelope glycoproteins, $8789-\mathrm{m}$ and $8672-\mathrm{m}$, were efficiently incorporated into iscoms, which has also been demonstrated for the cleavage site mutated precursor envelope glycoprotein of FIV ${ }^{14}$.

No differences in antibody reactivity of a panel of 15 Moabs were found between the wild type and cleavage site mutated 8672 and 8789 envelope glycoproteins, except for the abrogated recognition of the $8789-\mathrm{m}$ protein by Moab KK16. Sequence analysis showed that 
during PCR used for mutation of the cleavage site, a mutation had been introduced in the region where the reactivity of KK16 was mapped ${ }^{21}$ (position 619, C to $\mathrm{G}$ mutation). This did not influence the recognition of all the other Moabs, including those that recognize a conformation-dependent epitope, indicating that the overall conformational integrity of $8789-\mathrm{m}$ had remained intact.

The capacity of different adjuvants to enhance the antibody response was compared using the $8789-\mathrm{m}$ envelope glycoprotein. This protein was selected on basis of its reactivity with $\mathrm{KK} 5, \mathrm{KK} 9$ and $\mathrm{KK} 56$ and its ability to induce high VN titres (Figures 4 and 5). The highest titres of SIV-specific antibodies were found in rats immunized with the $8789-\mathrm{m}$ iscoms. This is in agreement with previous studies in which monkeys immunized with SIV proteins also showed a higher envelope antibody response with SIV-envelope proteins incorporated into iscoms than adjuvanted with $\mathrm{MDP}^{5}$. However, in rabbits the HIV-1 envelope protein adjuvanted with MDP-tsl was shown to induce a higher antibody response than HIV-1 envelope protein incorporated into the iscom matrix using a multiple immunization schedule ${ }^{16}$. This discrepancy may be due to the quality of the respective preparations, the animal species or to differences in the immunization schedule used.

In conclusion, our results indicate that sequence changes occurring during in vivo passage, result in major changes both in antigenicity and immunogenicity of the envelope glycoproteins of SIV. The availability of envelope proteins with distinct variable regions may offer the possibility to study their protective value in vitro and in vivo against a wider range of virus variants, but may also offer the possibility of sequential immunization to prime and boost for an antibody response directed against conserved regions in the absence of a secondary immune response to variable regions.

\section{ACKNOWLEDGEMENTS}

Dr K. Kent and the MRC AIDS directed programme are kindly acknowledged for the gift of the Moabs. We thank Dr B. Moss and Dr S. Chakrabarti for the gift of the pSC65 plasmid vector. Professor Dr B. Währen is kindly acknowledged, for the gift of the MDP-tsl adjuvant. J.S. Teppema is acknowledged for the electron microscopy on the iscom preparations and J. Groen for helpful technical discussions. We thank R. van Kinderen and K. van Essen for biotechnical assistance. Ms W. Witkamp and Ms C. Kruyssen are acknowledged for assistance in preparing the manuscript. This investigation was supported by the Dutch Council for Health Research (RGO) and the Praeventiefonds (grant no. 90.052 and 28-2128, respectively).

\section{REFERENCES}

1 Desrosiers, R.C. and Letvin, N. Animal models for acquired immunodeficiency syndrome. Rev. Infect. Dis. 1987, 9, 438446

2 Nixon, D.F., Broliden, K., Ogg, G. and Broliden, P.-A. Cellular and humoral antigenic epitopes in HIV and SIV. Immunology 1992, 76, 515-534

3 Cranage, M., Stott, J., Mills, K. et al. Vaccine studies with the $32 \mathrm{H}$ reisolate of SIVmac251: an overview. AIDS Res. Human Retrovir. 1992, 8, 1479-1481
4 Osterhaus, A.D.M.E., De Vries, P. and Heeney, J. AIDS vaccine developments. Nature 1992, 355, 684-685

5 De Vries, P., Heeney, J.L., Boes, J. et al. Protection of rhesus macaques from SIV infection by immunization with different experimental SIV vaccines. Vaccine 1994, 12, 1443-1452

$6 \mathrm{Hu}$, S.-L., Abrams, K., Barber, G.N. et al. Protection of macaques against SIV infection by subunit vaccines of SIV envelope glycoprotein gp160. Science 1992, 255, 456-459

7 Ahmad, S., Lohman, B., Marthas, M. et al. Reduced virus load in rhesus macaques immunized with recombinant gp160 and challenged with simian immunodeficiency virus. AlDS Res. Human Retrovir. 1994, 10, 195-204

8 Israel, Z., Ednonson, P.F., Maul, D.H. et al. Incomplete protection but suppression of virus burden elicited by subunit simian immunodeficiency virus vaccines. J. Virol. 1994, 68 , 1843-1845

9 Kitchin, P.A., Cranage, M.P., Baskerville, M.P. et al. Titration of SIVmac251 (32H isolate) in cynomolgus macaques for use as a challenge in vaccination studies. In: Proceedings of the International TNO Meeting on Animal Models in AIDS (Eds Horzinek, M.C. and Schellekens, H.). Elsevier, Amsterdam, 1990, pp. 115-129

10 Cranage, M.P., Cook, N., Johnstone, P. et al. SIV infection of rhesus macaques: in vivo titration of infectivity and development of an experimental vaccine. In: Proceedings of the International TNO Meeting on Animal Models in AIDS (Eds Horzinek, M.C. and Schellekens, H.). Elsevier, Amsterdam 1990, pp. 103-113

11 Niphuis, H., Dubbes, R.H., Ten Haaft, P.J.F. et al. Infectivity and virulence of cell-associated SIVmac after single passage in vivo. AIDS 8, 1730-1731

12 Kieny, M.P., Lathe, R., Rivière, Y. et al. Improved antigenicity of the HIV env protein by cleavage site removal. Protein Engng 1990, 2, 219-255

13 Mackett, M. Smith, G.L. and Moss, B. General method for production and selection of infectious vaccinia virus recombinants expressing foreign genes. J. Virol. 1984, 49 , 857-864

14 Rimmelzwaan, G.F., Siebelink, K.H.J., Huisman, R.C., Moss, B and Osterhaus, A.D.M.E. Removal of the cleavage site of recombinant FIV envelope protein facilitates incorporation of the surface glycoprotein in immune stimulating complexes. J. Gen. Virol. 1994, 75, 2097-2102

15 Allison, A.C. and Byars, N.E. An adjuvant formulation that selectively elicits the formation of antibodies of protective isotypes and of cell-mediated immunity. J. Immunol. Methods 1986, 95, 157-168

16 Levi, M., Rudén, U., Birx, D. et al. Effects of adjuvants and multiple antigen peptides on humoral and cellular immune responses to gp160 of HIV-1. J. AIDS 1993, 6, 855-864

17 Bos, E.S., Van Der Doelen, A.A., Van Rooy, M. and Schuurs, A.H.W.M. 3,3',5,5'-Tetramethyl-benzidine as an Ames test negative chromogen for horse-radish peroxidase in enzyme immunoassay. J. Immunoassay 1981, 2, 187

18 Javaherian, K., Loanlois, A.J., Monefiori, D.C. et al. Studies of the conformation-dependent neutralizing epitopes of Simian Immunodeficiency Virus envelope protein. J. Virol. 1994, 68, 2624-2631

19 Almond, N., Jenkins, A., Slade, A., Heath, A., Cranage, M. and Kitchin, P. Population sequence analysis of a simian immmunodeficiency virus $(32 \mathrm{H}$ reisolate of SIVmac251): a virus stock used for international vaccine studies. AIDS Res. Human Retrovir. 1992, 8, 77-88

20 Jentoft, N. Why are proteins O-glycosylated? Trends Biochem. Sci. 1990, 15, 291-294

21 Kent, K.A., Gritz, L., Stallard, G. et al. Production and characterization of monoclonal antibodies to simian immunodeficiency virus envelope glycoproteins. AIDS 1991, 5, 829-836

22 Kent, K.A., Rud, E., Corcoran, T. et al. Identification of two neutralizing and eight non-neutralizing epitopes on simian immunodeficiency virus envelope using monoclonal antibodies AIDS Res. Human Retrovir. 1992, 8, 1147-1151

23 Javaherian, K., Langlois, A.J., Schmidt, S. ot al. The principal neutralization determinant of simian immunodeficiency virus differs from that of human immunodeficiency virus type 1. Proc. Natl Acad. Sci. USA 1992, 89, 14181422

24 Ferguson, M., Wood, D.J. and Minor, P.D. Antigenic structure of poliovirus in inactivated vaccines. J. Gen. Virol. 1993, 74, 685-690 
25 Overbaugh, J. and Rudensey, L.M. Alterations in potential sites for glycosylation predominate during evolution of the simian immunodeficiency virus envelope gene in macaques. J. Virol. 1992, 66, 5937-5948

26 Overbaugh, J., Rudensey, L.M., Papenhausen, M.D. Benveniste, R.E. and Morton, W.R. Variation in Simian Inmmunodeficiency virus env is confined to $V_{1}$ and $V 4$ during progression to simian AIDS. J. Virol. 1991, 65, 7025-7031

27 Almond, N., Jenkins, A., Heath, A.B., Taffs, L.F. and Kitchin, P. The genetic evolution of the envelope gene of Simian Immunodeficiency Virus in Cynomolgus macaques infected with a complex virus pool. Virology 1992, 191, 996-1002

28 Wolfs, T.F.W., Zwart, G., Bakker, M. and Goudsmit, J. HIV-1 genomic RNA diversification following sexual and parenteral transmission. Virology 1992, 189, 103-110

29 Zhang, L.Q., MacKenzie, P., Cleland, A., Holmes, E.C., Leigh Brown, A.J. and Simmonds, P. Selection for specific sequences in the external envelope protein of human immunodeficiency virus type 1 upon primary infection. J. Virol. 1993, 67, 3345-3356

30 Zhu, T., Mo, H. Wang, N., Nam, D.S., Cao, Y., Koup, A. and Ho, D.D. Genotypic and phenotypic characterization of HIV-1 in patients with primary infection. Science 1993, 261, 1179-1181
31 Choi, W.S., Collignon, C., Thiriart, C., Burns, D.P.W., Stott, E.J., Kent, K.A. and Desrosiers, R.C. Effects of natural sequence variation on recognition by monocional antibodies that neutralize Simian Immunodeficiency Virus infectivity. J. Virol. 1994, 68, 5395-5402

32 McBride, B.W., Corthals, G., Rud, E., Kent, K., Webster, S., Cook, N. and Cranage, M.P. Comparison of serum antibody reactivities to a conformational and to linear antigenic sites in the external envelope glycoprotein of simian immunodeficiency virus (SIVmac) induced by infection and vaccination. J. Gen. Virol. 1993, 74, 1033-1041

33 Voss, G., Dittmer, U., Coulibaly, C., Makoschey, B., Petry, H. Lüke, $W$. and Hunsmann, $G$. Differences in the $B$ and $T$ cell immune response to the envelope glycoprotein $130(\mathrm{gp} 130)$ of the macaque strain of simian imimunodeficiency virus (SIVmac), induced by immunization of rhesus macaques with virusderived or vacc nia virus-expressed gp130. J. Gen. Virol. 1993 , 74, 1757-1763

34 Modrow, S., Hahn, B.M., Shaw, G.M., Gallo, R.C., Wong-Staal, $F$. and Wolf, $H$. Computer assisted analysis of envelope protein sequences of seven human immunodeficiency virus isolates. J. Virol. $1987,61,570-578$ 